\title{
A Note on these "Notes from the Field"
}

\author{
Michael Gurstein \\ New Jersey Institute of Technology < gurstein@adm.njit.edu >
}

The three articles in the cluster of "Notes from the Field," though representing three very different national and institutional contexts are in fact, remarkably complementary.

Klaus Stoll's article on bringing WiFi to El Chaco is a fine example of how a community is moving forward and overcoming obstacles and "leapfrogging" into advanced methods of connectivity through WiFi. At the same time the community is "appropriating" the technology for its own use and developing a variety of strategies and applications for subsequent "effective use".

The open letter from the Keewaytinook Okimakanak brings the activities in El Chaco into the wider context of how governments can and should play a role in ensuring the broadest possible access to advanced levels of connectivity. The letter argues forcefully that access to connectivity and Information and Communications Technologies can be transformative for local opportunities even in the remotest regions. The benefits that will flow as a consequence suggests that national investment in these areas should be of the highest priority.

The article prepared by Sascha Meinrath on behalf of the Champaign-Urbana Community Wireless Network and first National (US) Summit for Community Wireless Networks provides a sense of the opportunities which wireless enabled broadband connectivity presents. Writing from the perspective of someone who understands the technology and the directions of its developments, Meinrath is implicitly presenting a challenge and a plan of action for realizing these opportunities.

Together these three articles represent a very significant "manifesto" for taking the discussion about community based Wireless and Broadband into all spheres of development, development funding and development policy and give the strongest possible argument of the opportunity and need to incorporate Wireless along with broadband into the mainstream of community informatics thinking and applications. 